\title{
Tissue Culture, Anatomical and Morphological Studies of Triphasia trifolia (Burm. f.) P. Wilson
}

\author{
S. Abdullah, R.M. Taha, N.A. Hasbullah, N. Mohamed, H. Elias and N.W. Haron \\ Institute of Biological Sciences \\ Faculty of Sciences \\ University of Malaya \\ 50603 Kuala Lumpur \\ Malaysia
}

Keywords: anatomical, bundles, Triphasia trifolia (Burm. f.) P. Wilson, regeneration, vascular oils gland, SEM

\begin{abstract}
Comparative anatomical studies were carried out on in vivo plants of Triphasia trifolia (Burm. f.) P. Wilson and in vitro plantlets of the same age. To get the in vitro plantlets, explants were cultured on MS (Murashige and Skoog) media supplemented with different concentrations and combinations of hormones. The explant sources of Triphasia trifolia (Burm. f.) P. Wilson were obtained from cotyledons, leaves, stems, roots and shoot tips that were placed under conditions of 16 hours light and 8 hours dark. The optimum media for regeneration was MS supplemented with $1.0 \mathrm{mg} / \mathrm{L}$ BAP and $1.0 \mathrm{mg} / \mathrm{L}$ NAA. Cotyledon explants were found to be the most responsive. Regeneration of complete plantlets was achieved from cotyledon explants after about 4 months in culture. Sectioning was done to study the characteristics of the respective vascular bundles, shape of cells, palisade cell layers, presence of oil glands, druse and cuticle layers. Vascular bundles of in vivo leaves were extremely well developed compared to those in in vitro leaves. The vascular bundle of the in vivo leaf showed well developed xylem. However, the xylem and phloem cells of the in vitro leaf were very poorly developed which is one of the features of in vitro plants. Scanning electron microscope (SEM) studies were also carried out on the in vivo and in vitro plantlets to observe differences on the leaf surface.
\end{abstract}

\section{INTRODUCTION}

Triphasia trifolia (Burm. f.) P. Wilson is found frequently in tropical Asia especially in gardens (Britton, 1965). It is a glabrous spiny shrub, apparently introduced to India from China (Prain, 1903). It is also known to be found in Key West, lower Florida Keys (Long, 1971). It has been recorded as common in Peninsular Malaysia but is believed to be an escape in that country (Hooker, 1961). Its natural centre of origin is unknown but it is probably from Malaya (Hume, 1957). Bailey (1973) also believed that it originated from Malaya and stated that it is grown in warm countries sometimes for ornamental purposes. Triphasia trifolia (Burm. f.) P. Wilson has a few synonyms such as Triphasia aurantiola (Lour.), Limonia tripfoliata Linn., Limonia trifolia Burm. f., and Triphasiatrifoliata D.C. (Merrill, 1928). Triphasia trifolia goes by a number of vernacular names, lime berry in English and limaukiah, limaukikir, limauringkit in Malay (Verheij and Coronel, 1992). The leaves are used for treating diarrhea, colic, skin diseases and are also used in cosmetics in Indonesia (Chopra, 1969). The fruits and leaves are also claimed to be a medication for respiratory diseases. The leaves are applied to the abdomen to treat bowel complaints (Ruangrungsi et al., 1993). Syrup from the mucilaginous parts of the fruit (seed removed) is taken as an expectorant. Limoids (Maier et al., 1969) have been found in Triphasia trifolia and will provide a sound basis for their use as a chemotaxonomic indicator (Dreyer et al., 1971). The coumarin, isopimpinelin, was isolated from the seeds of this species along with aurapen, heraclenol, murrangatin, bajakangelicin, mexoticin andmeranzin hydrate from the leaves (Ruangrungsi et al., 1993). Velez and Magadan (1986) succeeded in extracting a new alkaloid from Triphasia trifolia, that is, methalhalfordia. There is a possibility that the coumarins in Triphasia trifolia (Burm. f.) 